\title{
Fast and frugal innovations in response to the COVID-19 pandemic
}

\author{
Necessity has been the mother of invention in the response to the COVID-19 pandemic, triggering many an \\ innovation, often without the luxury of time to test these makeshift solutions to pressing problems. But there is \\ much to be learned from times of crisis for times of plenty.
}

\section{Matthew Harris, Yasser Bhatti, Jim Buckley and Dhananjaya Sharma}

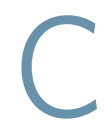
OVID-19 has required unprecedented responses from all countries. Such has been the speed and severity of the pandemic that few countries have been afforded the luxury of following traditional processes of testing and trialing new technologies, processes and medicines. Countries that have delayed their response to COVID-19 seem to be faring worse. The lack of time and resources available to respond to the crisis, as well as the need for rapid scaling in every context, has led to an explosion of innovative responses.

There have been some extraordinary moves. India and Pakistan are refitting their rolling stock of trains to become hospital wards for patients with COVID-19 ${ }^{1}$. China constructed a 1,000-bed hospital in 10 days $\left(\right.$ ref. $\left.^{2}\right)$. Distilleries have pivoted to produce millions of bottles of hand sanitizer ${ }^{3}$.

Nations that uphold free choice, movement and competition have suddenly foregone many fundamental values and privileges. For example, in addition to enacting widespread social-distancing measures, the UK, in a landmark deal, has commissioned all of its private-sector hospitals for use by the National Health Service, at cost, expanding capacity by 8,000 beds $^{4}$.

These responses bear the hallmarks of so-called 'frugal innovation'-that is, doing more, with less, for the many, and being creative, innovative and resourceful in the face of institutional voids and resource constraints ${ }^{5}$. This has been the reality of the experience of many low- and middle-income countries, even before the COVID-19 pandemic, which is why so many frugal innovations emerge from these contexts ${ }^{6-8}$. Frugal innovation has been touted for its merits in serving the needs of the poor or the bottom of the pyramid ${ }^{9}$, formaking business internationally competitive $e^{10}$ and forachieving sustainable development ${ }^{11}$.

Frugal innovation in healthcare does not mean low quality but instead means the ability to provide safe healthcare in the best way possible under given circumstances and constraints. Challenging as the current public-health crisis is, frugal innovation provides opportunities to expand access to care and to ensure that the care, although perhaps not perfect (yet), is good enough under the current circumstances. While there is a predominant emphasis on affordability and low cost in frugal innovation, there are many other associated drivers, competencies and dimensions as well $^{12}$. Of these, we believe three approaches help us to relate the examples we have encountered thus far in responding to the COVID-19 threat: repurposing, reuse and rapid deployment. Although it is not an exhaustive list, Table 1 describes several such frugal innovations in some detail.

The accelerated pace of clinical-trial approval around the world, including in the USA and Europe, has shown how traditionally conservative institutions can act rapidly in times of urgency. And given the imperative to scale up protective equipment, ventilators, medicines and potential vaccines to the whole world, underpinning all of these approaches is the need to contain costs toward affordability. Although many may be willing to pay anything for containment or cure of COVID-19, governments worldwide can ensure fairness and equity only if the solutions are affordable to individuals and to society as a whole.

These innovations are not without their challenges. Some have not been field tested, let alone evaluated, in randomized, controlled trials. There are other risks, too, with one person reported to have died from the improper repurposing of a form of chloroquine phosphate for prophylaxis following US President Trump's advocacy of the drug ${ }^{13}$. However, in the context of this rapidly evolving pandemic, during which even national lockdowns threatening the economic, social and cultural fabric of society have also not been first evaluated and tested, there is merit in using these frugal solutions, improving on them and sharing the resultant findings so that they can bring benefit and needed care to as many victims of COVID-19 as possible.

The physical barrier to co-creation posed by social distancing has been mitigated partly through the greater use of digital tools. Indeed, where the COVID-19 pandemic has witnessed the most effective innovation has been in the sharing of new knowledge though social media, transcending the traditional boundaries of knowledge production, dissemination and consumption. Such has been the speed with which local, regional and national experiences have been shared, nimbly, rapidly and without borders, that it may have left many wondering whether this will disrupt traditional academic publishing altogether.

There are many underlying lessons. Necessity is the mother of invention, and human beings can be resourceful, particularly in crisis, in coming up with frugal solutions that get the job done. It is sometimes necessary to forego high regulatory standards in order to rapidly address new demands at low cost, and although the imperative for frugal approaches to healthcare provision has been witnessed in developing countries for many years, the value of humble approaches to innovation is now being seen even in the most technologically advanced countries. It remains to be seen whether this global crisis will permanently disrupt how innovation occurs in healthcare. Furthermore, the unconscious biases faced by researchers from low-income countries ${ }^{14-20}$ may be mitigated by this improved global knowledge flow, and this may result in improved uptake of innovations from these contexts, so-called 'reverse innovation'21,22.

After the world finishes dealing with the COVID-19 pandemic, the important lesson for humanity here might be to learn from everyone and for everyone. The pandemic may serve as the greatest leveler of our time and teach us to recognize the fragility in all our healthcare systems. There may be, at least, this one positive outcome. 
Table 1 | A selection of notable frugal innovation responses in the COVID-19 pandemic

\begin{tabular}{|c|c|}
\hline & Features \\
\hline Hydroxychloroquine & $\begin{array}{l}\text { Anecdotal evidence and case series have } \\
\text { suggested some benefit as prophylaxis } \\
\text { and treatment when used in combination } \\
\text { with azithromycin and zinc sulfate }{ }^{23} \text {. }\end{array}$ \\
\hline $\begin{array}{l}\text { Ventilator } \\
\text { multipliers }\end{array}$ & $\begin{array}{l}\text { Open-source 3D-printed device available } \\
\text { to connect multiple ventilator hoses to a } \\
\text { single ventilator machine. Two colors are } \\
\text { used to identify inhalation and exhalation } \\
\text { components. Using a Nellcor Puritan } \\
\text { Bennett } 840 \text { Ventilator System, innovators } \\
\text { were able to provide a tidal volume of } \\
450 \text { per patient, inspiratory pressure of } \\
25 \mathrm{~cm} \mathrm{H}_{2} \mathrm{O} \text { and positive end-expiratory } \\
\text { pressure of } 10 \mathrm{~cm} \mathrm{H}_{2} \mathrm{O} \text { (S. Anwar, personal } \\
\text { communication). }\end{array}$ \\
\hline
\end{tabular}

Portable and OxVent (UK) has redesigned ventilators open-source designs to use and repurpose $90 \%$ off-the-shelf of ventilators parts ${ }^{27}$. Medtronic (Ireland) is sharing its portable ventilator design specifications and code free of charge to all manufacturers worldwide under a free license valid until the official pandemic emergency is declared over by the $\mathrm{WHO}^{28}$. AgVa Healthcare (India) is also sharing designs of its portable ventilator, which weighs $\sim 3.5 \mathrm{~kg}$, oxygenates room air and costs US $\$ 2,000$, with much of the software functionality provided by an app installed on the operator's smartphone (https://www.agvahealthcare.com/ covid-19) ${ }^{29}$. By comparison, contemporary ventilators such as the Siemens Maquet Servo-i weigh $20 \mathrm{~kg}$, require medical air and cost $>$ US $\$ 10,000$.

Face masks and $\quad$ A4 acetate sheet used for overhead visors

Aerosol boxes for intubation

projector presentations: a simple hole-punch is used to punch two holes on either side of the sheet, and the ties of a regular face mask are threaded through the four holes before the mask is secured around the head in the normal way; the extended protection of the acetate sheet covers the eyes and neck area to protect the wearer from aerosols.

A transparent shelf made of acrylic or transparent polycarbonate sheet placed

\section{Frugal innovation Opportunities for scaling approach}

Repurposing from malaria prophylaxis and treatment

Rapid production and reuse of existing ventilator machines

Repurposing of existing assets in the supply chain and reuse of the power of smartphones over a supine patient during intubation; this permits access to the patient from the front end while providing full visual clarity overhead, and reduces aerosol contamination of the anesthetist. After each intubation, the box can be cleaned with $70 \%$ alcohol or bleach to be readied for reuse (sourced as the TracheoBox).

Cheap and readily available. The its use for COVID-19 prophylaxis prophylaxis in low-risk groups ${ }^{25}$. ventilator sharing ${ }^{26}$
Reuse of existing material and assets available widely in the office place

Reuse of existing material government of India has approved (at $400 \mathrm{mg}$ twice a day on first day, then $400 \mathrm{mg}$ once weekly for 7 weeks) ${ }^{24}$. The American College of Cardiology has produced a risk-classification system to ascertain whether it can be used as

3D printing enables rapid prototyping and production. Designs for production are available open source. Potential to ventilate up to seven patients on one ventilator machine could radically transform access to urgent therapy when needed. Tube lengthening to up to 20 feet does not alter ventilation performance, per a protocol released by New York-Presbyterian Hospital for

Open-source designs enable distributed manufacturing and allow countries to tailor designs suitable for their own manufacturing capabilities. Portability, simplicity and use of fewer components allow ramping-up of production and distribution. Such features conform to the UK's Rapidly Manufactured Ventilator System specifications, which call for robustness, intuitive operation and use of local materials in anticipation of global supply chain disruptions ${ }^{30}$.

Extremely simple workaround to partially obviate the need for full face protection. The transparent sheet enables full vision and protects the wearer against aerosol contamination of the eyes and surrounding area. In the absence of full PPE, this simple workaround might afford some protection where risk of aerosol spread is high.

In the absence of full PPE, this simple innovation can provide some useful, needed protection against aerosol spread of COVID-19, particularly for anesthetists. Compared to intubating with full PPE, the TracheoBox might provide improved usability.

\section{Challenges}

The evidence base is currently weak and requires formal evaluation and trials. The drug is available by prescription only, and carries cardiac risk (QT prolongation), so it is unsuitable for people with heart disease.

The confusing array of tubing around the ventilator machine could lead to human error. Testing under lab conditions has demonstrated its potential, but it has not yet been field tested or tested on human subjects.

Due to limited features, such ventilators, although touted as useful for many patients with COVID-19, may not be suitable for all types of patients.

Full protection is unlikely, and successful use is probably user dependent. Cross-contamination is likely, but not inevitable. Evidence of field testing is unavailable. It can be uncomfortable for the user.

There is no evidence of effectiveness available. Usability might be restricted, as it provides somewhat limited arm movement for intubation. It is unclear whether it provides full protection from aerosols. 
Table 1 | A selection of notable frugal innovation responses in the COVID-19 pandemic (Continued)

\section{Features}

Task shifting in ICUs

CHW-led response at community level

DIY face masks

Prone self-ventilation

\section{Frugal innovation Opportunities for scaling} approach

Drawing on lean management techniques, Rapid ICUs can be reorganized to ensure that more rapid, expanded care is provided to a far larger number of patients than are usually found in regular ICUs. Lower-level healthcare assistants or nurses can prepare the patients in groups, with consultants or specialists intubating one patient after another in rapid succession. Such models of care have been used in the Aravind Eye Hospital, India, for several years, which has led to a substantial increase in the number of cataract operations that can be performed by one ophthalmic surgeon, relative to similar operations conducted in the USA ${ }^{8}$.

\section{Training lay $\mathrm{CHWs}$ to provide} household-level advice and support during an epidemic provides a distributed public-health response where it is needed most: in households. $\mathrm{CHWs}$ are able to prevent, detect and respond to epidemics, as demonstrated from longstanding experience of scaled community health workforces in Brazil, Ethiopia, India and Pakistan that have enabled effective responses during Zika, Ebola and cholera epidemics ${ }^{31-33}$. Using risk-assessment tools based on the most basic protocols, CHWs can identify at-risk groups, refer patients to the health system, understand the local determinants of health and develop community-wide interventions to support the national response. Task shifting to lower-level healthcare workers is effective and efficient, given their shorter training times and lower salary costs.

Although the WHO suggests there is no evidence that face masks provide sufficient protection, the Czech Republic is one of a few countries to make wearing a face mask mandatory ${ }^{35}$. This has spurred a do-it-yourself movement with people making their own masks using household material and domestic sewing machines.

Although placing patients in a prone position is an acceptable practice for ventilated patients, the COVID19 pandemic has led clinicians to try it for non-ventilated hospitalized patients - a completely novel, frugal clinical intervention. The prone position improves pleural pressure and reduces lung atelectasis in patients with acute respiratory distress syndrome, with increased lung recruitment in the dorsal lungs due to the position of the heart and other mediastinal structures. V/Q matching and oxygenation are improved, and this may obviate the need for treatment in the $\mathrm{ICU}^{36}$. infrastructure and with two more sites planned elsewhere repurposing of human resources

Repurposing of human resources to improve existing or develop new skills

(
for and how.
Reuse of existing material, skills and assets for rapid production

Simple, no-cost technique to improve outcomes transformation of makeshift hospitals: for example, NHS existing operating Nightingale in the UK has 4,000 beds, in the country. Such expansion of capacity requires task-shifted roles so expert capacity can be leveraged across a wide range and number of cases.

Online massive open online courses to train $\mathrm{CHWs}$ are available from several higher-education institutions. The WHO's Health Emergency Programme Learning and Capacity Development Unit will launch online training for COVID-19 response soon. In the UK, the launch of NHS Volunteers has seen 700,000 people register to provide support to those in need, although so far there has been little guidance or policy about what the volunteers will be used

With social distancing in place, idle workforce in homes and other places can be utilized to produce protective equipment. For instance, in Pakistan and the Czech Republic, the prison service has distributed the task to prison inmates $^{34}$.

Several randomized, controlled trials have shown improved oxygenation compared with that in the supine position, from improved pulmonary secretion drainage, alveolar recruitment and reduced atelectasis. There is reduced likelihood of ventilator-associated lung injury ${ }^{36}$.

\section{Challenges}

Such lean processes require foregoing all patient confidentiality or exclusivity found in normal isolation cubicles.

There are regulatory hurdles for the accreditation of training programs in some contexts. The debate on whether $\mathrm{CHWs}$ should be paid employees or volunteers is longstanding; however, a fully effective workforce will require a funded, salaried, government-sponsored role $^{34}$.

There is little evidence that household fabric and materials can provide effective protection.

Overall, evidence for improved mortality is unclear, although the PROSEVA study $(n=466)$ demonstrated an absolute risk reduction of mortality of $17 \%$ at 28 days $(95 \% \mathrm{Cl}, 9.1-24.4 \%$; $P<0.001)^{37}$. It is useful only when implemented by those with experience of prone positioning, as it may result in facial edema and airway obstruction. 
Table 1 | A selection of notable frugal innovation responses in the COVID-19 pandemic (Continued)

\section{Features}

Frugal ventilator machines
The Mercedes Formula One team collaborated with University College London to reverse engineer a continuous positive airway pressure breathing aid in less than $100 \mathrm{~h}$ from the initial meeting to production of the first device. An Oxford and King's College collaboration has developed a ventilator made of only 40 components, $90 \%$ of which are off-the-shelf components already in the NHS supply chain ${ }^{27}$. Mercedes-Benz and Tesla are applying their vast manufacturing capability to produce ventilator parts 38,39 .

\section{Frugal innovation Opportunities for scaling} approach

\section{Repurposing and The former device was granted approval} reuse of existing by the UK Medicine and Healthcare material for rapid Product Regulatory Agency in record production time, with the aim of rapid production of thousands of them ${ }^{40}$

\section{Challenges}

Order fulfilment and delivery has stalled in early stages in some localities, with a view of ramping up supply over the short term.

WHO, World Health Organization; PPE, personal protective equipment; CHW, community health worker; ICU, intensive care unit; $\mathrm{NHS}$, National Health Service;

\section{Matthew Harris ${ }^{1 凶}$, Yasser Bhatti ${ }^{2}$}

Jim Buckley (D) ${ }^{3}$ and Dhananjaya Sharma ${ }^{4}$

${ }^{1}$ Imperial College London, London, UK.

${ }^{2}$ Queen Mary University London, London, UK.

${ }^{3}$ Royal Free Hospital, London, UK. ${ }^{4}$ Department of Surgery, Government NSCB Medical College and Allied Hospitals, Jabalpur, India.

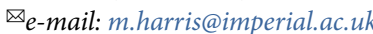

Published online: 11 May 2020

https://doi.org/10.1038/s41591-020-0889-1

References

1. Nandi, T. Livemint https://www.livemint.com/news/india/ see-pics-indian-railways-coaches-converted-to-isolation-wardsfor-coronavirus-patients-11585573012954.html (2020).

2. Ankel, S. Bus. Insider https://www.businessinsider.com/ how-china-managed-build-entirely-new-hospital-in-10-days2020-2 (2020).

3. India Today Web Desk. India Today https://www.indiatoday.in/ trending-news/story/coronavirus-vodka-company-to-make24-tons-of-hand-sanitisers-1658956-2020-03-24 (2020).

4. The Economist https://www.economist.com/britain/2020/03/26/ how-the-national-health-service-is-transforming-itself (2020).

5. Bhatti, Y., Basu, R., Barron, D. \& Ventresca, M. Frugal Innovation: Models, Means, Methods (Cambridge Univ. Press, 2018).

6. Bhatti, Y. et al. Health Aff. (Millwood) 36, 1912-1919 (2017).

7. Skopec, M., Issa, H. \& Harris, M. Br. Med. J. 397, 16205 (2019)

8. Govindarajan, V. \& Ramamurti, R. Harv. Bus. Rev. 91, 117-122 (2013).

9. Prahalad, C.K. The Fortune at the Bottom of the Pyramid: Eradicating Poverty Through Profits 5th anniversary edn (FT Press, 2009).

10. Govindarajan, V. \& Trimble, C. Reverse Innovation: Create For from Home, Win Everywhere (Harvard Business Press, 2012).

11. Prabhu, J. Phil. Trans. R. Soc. 375, 20160372 (2017).

12. Basu, R., Banerjee, R. \& Sweeny, E. J. Management Global Sustain 2, 63-82 (2013)

13. Haelle, T. Forbes https://www.forbes.com/sites/tarahaelle/2020/ 03/23/man-dead-from-taking-chloroquine-after-trump-toutsdrug-for-coronavirus/\#89604b72e91a (2020).

14. Harris, M., Weisberger, E., Silver, D. \& Macinko, J. Global Health 11, 45 (2015).
15. Harris, M., Macinko, J., Jimenez, G. \& Mullachery, P. Global Health 13, 80 (2017)

16. Harris, M. et al. Health Aff. 36, 11 (2017)

17. Cash-Gibson, L., Rojas-Gualdrón, D. F., Pericàs, J. M. \& Benach, J. PLoS One 13, e0191901 (2018).

18. Istratii, R. Convivial Thinking https://www.convivialthinking.org/ index.php/2020/02/29/decolonising-knowledge/ (2020).

19. Lokugamage, A. U., Ahillan, T. \& Pathberiya, S. D. C. J. Med. Ethics 46, 265-272 (2020).

20. McGillivray, B. \& De Ranieri, E. Res. Integr. Peer Rev. 3 , 5 (2018).

21. Hadengue, M., de Marcellis-Warin, N. \& Warin, T. Int. J. Emerg. Markets 12, 142-182 (2017).

22. Bhattacharya, O. et al. Global Health 13, 4 (2017).

23. Gautret, P. et al. Int. J. Antimicrob. Agents https://doi org/10.1016/j.ijantimicag.2020.105949 (2020).

24. Ministry of Health and Family Welfare. Gazette of India Extraordinary Notification, Part II - sec. 3(i), F. No. 18-03/2020-DC. GSR 219(E) (New Delhi, 2020).

25. Simpson, T., Kovacs, R. \& Stecker, E. Cardiology https://www.acc org/latest-in-cardiology/articles/2020/03/27/14/00/ventriculararrhythmia-risk-due-to-hydroxychloroquine-azithromycintreatment-for-covid-19 (2020)

26. Beitler, J. et al. https://emcrit.org/wp-content/uploads/2020/03/ Ventilator-Sharing-Protocol-Dual-Patient-Ventilation-witha-Single-Mechanical-Ventilator-for-Use-during-CriticalVentilator-Shortages.pdf (2020).

27. Univ. Oxford News \& Events http://www.ox.ac.uk/news/2020-03 31-ventilator-project-oxvent-gets-green-light-uk-governmentproceed-next-stage-testing (2020).

28. Etherington, D. Techcrunch https://techcrunch.com/2020/ 03/30/medtronic-is-sharing-its-portable-ventilator-designspecifications-and-code-for-free-to-all/ (2020).

29. Al Jazeera https://www.aljazeera.com/news/2020/04/india-toastersized-ventilator-fight-virus-200402090302355.html (2020).

30. Department of Health and Social Care. UK Government. Guidance: Rapidly manufactured ventilator system specification https://www.gov.uk/government/publications/coronaviruscovid-19-ventilator-supply-specification/rapidlymanufactured-ventilator-system-specification (2020).

31. Macinko, J. \& Harris, M. J. N. Engl. J. Med. 372, 2177-2181 (2015)

32. Wadge, H. et al. Brazil's Family Health Strategy: Using Community Health Care Workers to Provide Primary Care http://www.commonwealthfund.org/publications/ case-studies/2016/dec/brazil-family-health-strategy (The Commonwealth Fund, 2016).
33. Wiah, S., Subah, M. \& Varpilah, B. The BMJ Opinion Blog https://blogs.bmj.com/bmj/2020/03/27/prevent-detectrespond-how-community-health-workers-can-help-fightcovid-19/ (2020).

34. Haines, A., Falceto de Barros, E., Berlin, A., Heymann, D. L. \& Harris, M. J. Lancet 395, 11173-11175 (2020).

35. Hutt, D. Euronews https://www.euronews.com/2020/03/24/ coronavirus-czechs-facing-up-to-covid-19-crisis-by-makingmasks-mandatory (2020)

36. Henderson, W.R., Griesdale, D.E., Dominelli, P. \& Ronco, J.J. Can. Respir. J. 21, 213-215 (2014).

37. Guérin, C. et al. Prone positioning in severe acute respiratory distress syndrome. N. Engl. J. Med. 368, 2159-2168 (2013).

38. Sackur, S. BBC World News HARDTalk https://www.bbc.co.uk/ programmes/m000h3cb (2020).

39. Ohnsman, A. Forbes https://www.forbes.com/sites/alanohnsman/ 2020/03/30/medtronic-gives-away-ventilator-designspecs-in-coronavirus-fight-ahead-of-tesla-alliance/\#421422 9c4591 (2020).

40. UCL. UCL News https://www.ucl.ac.uk/news/2020/mar/ ucl-uclh-and-formula-one-develop-life-saving-breathing-aidsnhs (2020)

\section{Acknowledgements}

No funding was received in direct relation to this article. M.H. is supported in part by the NW London National Institute for Health Research (NIHR) Applied Research Collaboration. Imperial College London is grateful for support from the NW London NIHR Applied Research Collaboration and the Imperial NIHR Biomedical Research Centre. The views expressed in this publication are those of the authors and not necessarily those of the NIHR or the Department of Health and Social Care.

\section{Author contributions}

M.H. conceived of the article, wrote the first draft, and reviewed all subsequent drafts and the final version; Y.B. wrote the first draft and reviewed all subsequent drafts and the final version; and J.B. and D.S. reviewed all drafts and provided substantial intellectual content.

Competing interests

M.H. is a non-executive director of Primary Care International. 